\title{
Correction to: Susceptibility of nymphs and adults of Blattella germanica (Dictyoptera: Blattellidae) to Aspergillus terreus (Eurotiales: Trichocomaceae) infested via oral ingestion, contact, and bait methods: a comparative study
}

\author{
Yamina Djouhri ${ }^{1,2} \cdot$ Mahdia Saidi-Touati $^{2} \cdot$ Amina Benelmouffok $^{3} \cdot$ Mohamed Nadji Bouchtout $^{4}$
}

Published online: 26 February 2022

(c) The Author(s) under exclusive licence to The Japanese Society of Applied Entomology and Zoology 2022

\section{Correction to: Applied Entomology and Zoology https://doi.org/10.1007/s13355-022-00770-0}

In the original publication of the article, the values of " $\alpha \beta$ $\gamma \delta$ " were placed incorrectly in tables 1 and 2 .

The correct Tables 1 and 2 are provided in this correction article.

The original article has been corrected.

Publisher's Note Springer Nature remains neutral with regard to jurisdictional claims in published maps and institutional affiliations.

The original article can be found online at https://doi.org/10.1007/ s13355-022-00770-0.

Yamina Djouhri

djouhrim.yamina@gmail.com

1 Laboratory of Biodiversity and Environment: Interactions and Genomes, Faculty of Biological Sciences, University of Science and Technology Houari Boumediene, BP 32, El Alia Bab Ezzouar, CP 16000 Algiers, Algeria

2 Laboratory of Dynamics and Biodiversity, Team of Arthropods Biodiversity, Faculty of Biological Sciences, University of Science and Technology Houari Boumediene, BP 32, El Alia Bab Ezzouar, CP 16000 Algiers, Algeria

3 Mycology Department, Pasteur Institute of Algeria, Staouéli, Dély-Brahim, Algiers, Algeria

4 Laboratory of Cellular and Molecular Biology, Cytokine and NO Synthase Team, University of Science and Technology Houari Boumediene, BP 32, El Alia Bab Ezzouar, CP 16000 Algiers, Algeria 


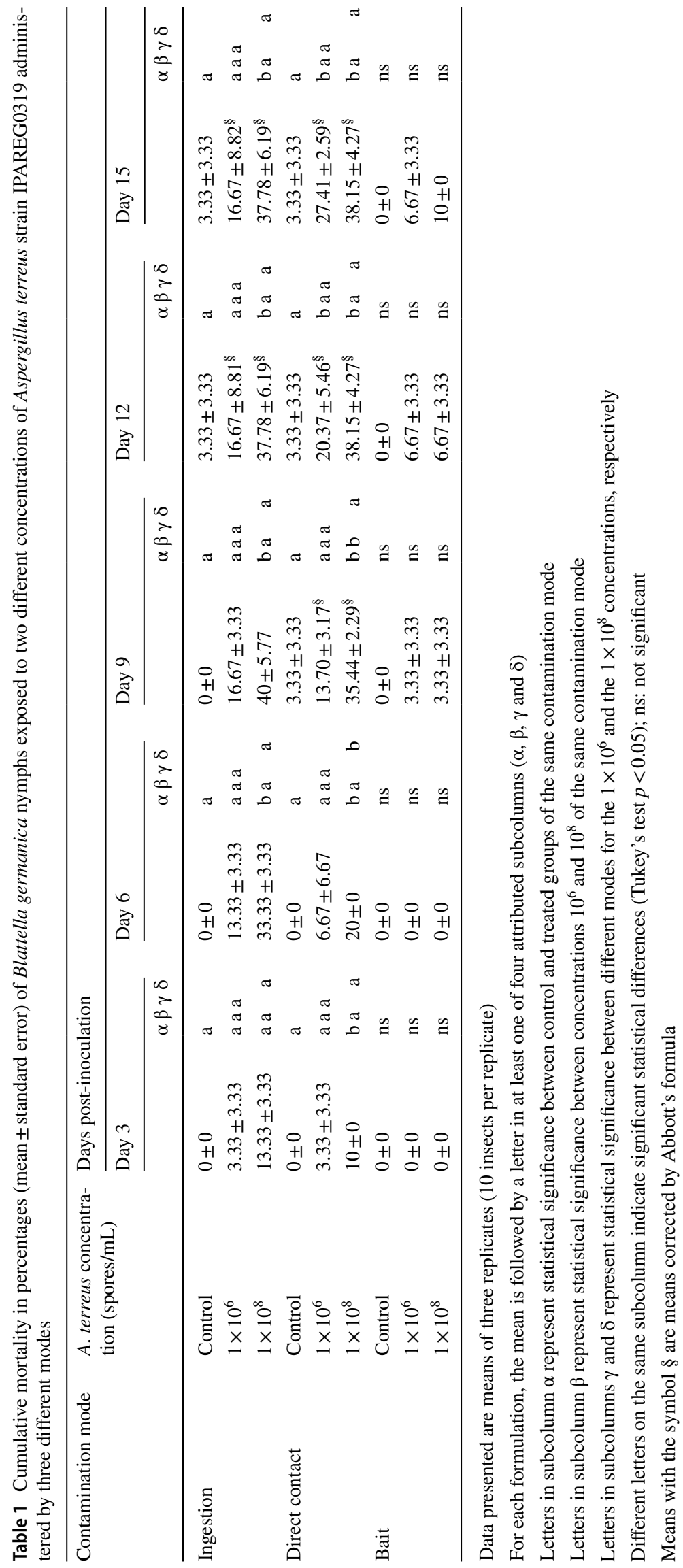




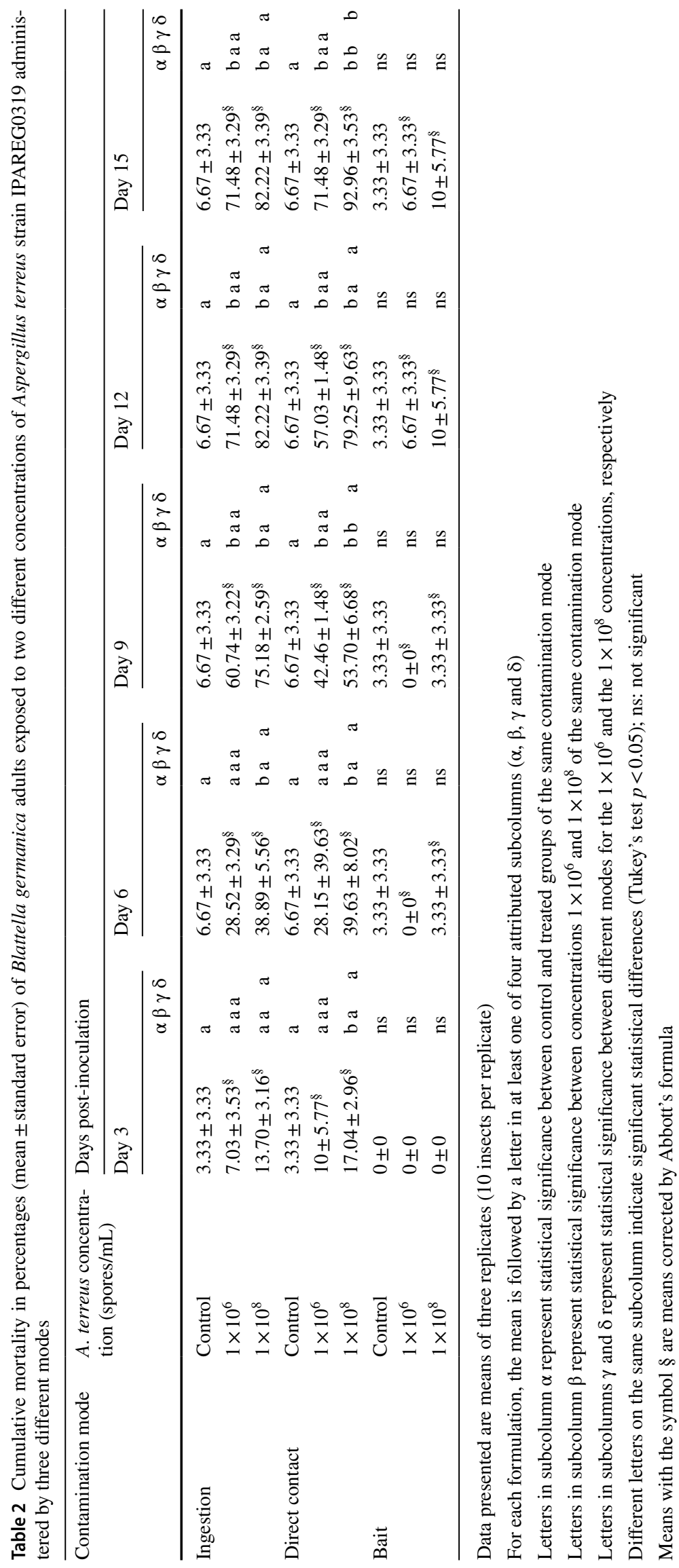

